\title{
Determination of the elimination costs of vibrations and dust transmission in refurbishment healthcare buildings works in Spain
}

\author{
Justo García-Sanz-Calcedo \\ University of Extremadura, Badajoz, Spain \\ E-mail:jgsanz@unex.es \\ Received 24 March 2019; accepted 3 April 2019 \\ DOI https://doi.org/10.21595/vp.2019.20684
}

Check for updates

Copyright (C) 2019 Justo Garcia-Sanz-Calcedo. This is an open access article distributed under the Creative Commons Attribution License, which permits unrestricted use, distribution, and reproduction in any medium, provided the original work is properly cited.

\begin{abstract}
The aim of this paper is to evaluate the average cost of preventive measures for noise insulation, vibrations and dust transmission in healthcare buildings, which guarantee environmental biosafety in renovation infrastructure works. 30 hospital reformation works carried out between 2004 and 2010 in Spain were analyzed. The average impact of the environmental biosafety measures incorporated in the project was $1.07 \%$ of the budget. The average cost of the actions was $5.5 € / \mathrm{m}^{2}$ in works in critical areas and $0.9 € / \mathrm{m}^{2}$ in the rest. In critical areas, the sectoring meant an average cost of $26.89 \%$ of the budget of the work and in the rest of areas of $29.48 \%$. It was concluded that the management of environmental biosafety in the works means a minimum cost, which reduces the transmission of noise, vibrations and dust, reducing the probability of nosocomial infection.
\end{abstract}

Keywords: biomedical engineering, biosafety, healthcare management, healthcare engineering, vibrations.

\section{Introduction}

Healthcare centers and hospitals are buildings that are undergoing to continuous refurbishment to adapt spaces, technology and facilities to the continuous advances of science [1]. These works are characterized by the fact that due to the intensity of this type of building, 24 hours a day, 365 days a year, they must be carried out with the healthcare center in operation [2].

It is known that the noise and vibrations generated by hospital renovation works make it difficult for patients to recover [3], increase the stress levels of their workers [4] and increase the risk of cardiovascular disease and hypertension. Also, noise and vibrations reduce the immune response and increase patient pain [5].

In addition, the incidence of construction works in a hospital environment has been demonstrated, increasing opportunistic fungal infections in hospitalized patients, especially in immune-compromised patients. The dust generated in these works is the main way of transmission of these fungi [6]. There is even a certain sanitary culture and sensitivity about the methodology to be used in the management of these works, mainly through the constitution of a Works Commission [7].

The management of the environmental biosecurity in a work supposes a low cost that minimizes the generation and transmission of noise, vibrations and dust. However, it is necessary to maintain a system of continuous recording of the environmental biosafety levels during the execution of the work, since on most occasions when high fungal counts are detected, it is not possible to identify the cause that produced them.

The costs of environmental biosecurity measures in hospital reform works, in which healthcare activity continues to be provided, and the guidelines followed in their development are not determined [8], although the relationship between outbreaks of nosocomial infections and the execution of works in healthcare centers is documented [9-11].

Before the start of a project, in the project development phase, health professionals must collaborate with the site technicians, identifying the risk groups and/or the criticality of the areas 
of action $[12,13]$.

Construction dust, rubble or building scrap can bring microorganisms into the patient care area. Suspension of ventilation filter systems leads to decreased air circulation. The entrance of dust from neighboring constructions to the healthcare institution can alter the normal circulation of the air.

There is bibliography to improve the management of the environmental biosecurity in phase of execution of works. In 2000, INSALUD, in collaboration with the Spanish Society of Preventive Medicine, Public Health and Hygiene, published the guide for the prevention and control of infections in hospitals under construction [14]. In Spain, once the transfer of health competencies to the autonomous regions has been completed, the management of hospital works has been developed with different criteria according to the autonomous community where it is carried out [15].

The American Institute of Architects, in its Guidelines for the Design and Construction of Hospitals and Health Services, states that all projects for the renovation and construction of hospitals and healthcare services require consultation with the infection control committee, engineers, architects, the institution's directors and security personnel [16].

In 2010, the Spanish Society of Infectious Diseases and Clinical Microbiology published a document to prevent fungal infection [17], which presents a set of guidelines for action and organization, based on avoiding the risk factors associated with nosocomial infections.

Molina et al. (2008), after five years of environmental surveillance of works in a hospital area, did not detect an increase in cases of Aspergillosis [18]. Benítez (2006) studied the environmental biosecurity in a hospital with large works, proposing different corrective and organizational measures [19]. However, there is no precedent for work that evaluates the cost of preventive biosafety measures.

The relationship between outbreaks of nosocomial infections and the execution of works in health centres has been documented for some time. Almost all the lines of work affect the management of the work once it begins, although in order to facilitate this management in the work phase, the first steps must be taken from the moment of conception of the need for the work.

The objective of this work is to quantify the economic cost of preventive measures to guarantee the elimination of noise, vibrations and dust transmission in refurbishment works of Spanish hospitals and to minimize risk factors, by means of methodological analysis of the works carried out.

\section{Methodology}

During the study, 30 hospital refurbishment or extension works carried out by the Extremadura Health Service (SES), carried out between 2004 and 2010 in Extremadura (Spain), with a budget of more than $€ 54,000,000$, were analyzed.

The documentation of each work, its execution project, as well as the incidents that were documented in the area of environmental biosecurity were reviewed in detail. In order to determine the impact on the Health and Safety conditions of the worksite, surveys and interviews were carried out with the Health and Safety coordinators.

The construction works were classified according to dust production in four groups, based on the document Construction related Nosocomial Infections in Patients in Health Care Facilities [20]. The areas affected by the works were classified into five zones according to their location, the affected area and their level of criticality, using as a basis the document Recommendations for the Surveillance, Prevention and Control of Infections in Hospitals on Works [21].

In each work, an Environmental Biosafety Project was carried out, drafted by the project designers, as a document with its own project entity, which contained the information related to the environmental biosecurity necessary for its development and implementation. This document was reviewed by the Works Commission and consisted of a Memorandum, Conditions Specifications, Plans and a Budget. 
Depending on the area, the risk to patients and the typology of the works, the set of measures needed to minimize dust generation, procedures, typology and the main characteristics of the sectorisation were determined. In this way, a sectorisation of the works was carried out, planned and agreed with the care teams, avoiding leaving the order in which the work was carried out to chance, seeking a balance between protection and the functionality of the hospital. Figure 1 shows an example of a biosecurity barrier installed on a hospital site.

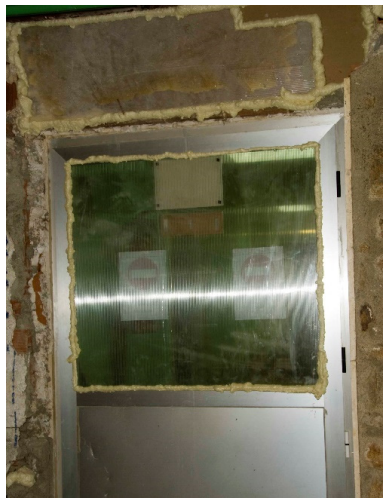

Fig. 1. Biosecurity barrier installed on a hospital site

The intervention areas were divided into three types: critical areas (Z1) representing $17 \%$ of the sample, areas adjacent to the critical areas (Z2) $33 \%$ and areas not included in the previous sections, called Z3, $50 \%$. For the purposes of this investigation, the critical zone was subdivided into two types depending on the size of the action: large actions (Z1a) and minor actions (Z1b).

\section{Results}

Fig. 2 shows the cost of the environmental biosecurity per unit area, depending on the area where the intervention takes place. It can be seen that the investment in environmental biosecurity ranged between 0.67 and $6.15 € / \mathrm{m}^{2}$, with a greater percentage impact on the smaller scale works carried out in critical areas $(\mathrm{Z} 1)$.

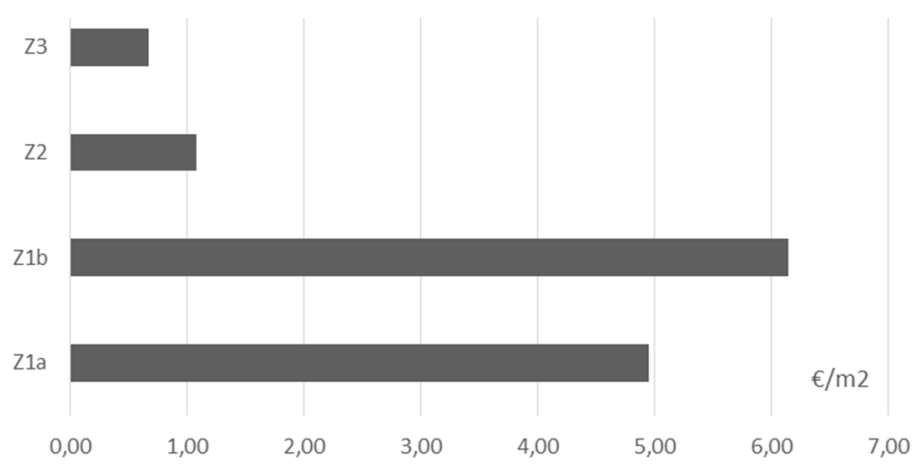

Fig. 2. Cost of the environmental biosecurity per unit of built area by areas of action

In small works carried out in critical units, the repercussion per unit area was $6.15 € / \mathrm{m}^{2}$. For larger projects, the average was $€ 4.95 / \mathrm{m}^{2}$. It was detected that the lower the risk of the intervention area, the lower the average repercussion per unit area.

Fig. 3 shows the relationship between the cost in environmental biosecurity and the budget for execution of the work, depending on the area. The average percentage repercussion of the environmental biosafety measures on the total budget of the work was $1.07 \%$. 


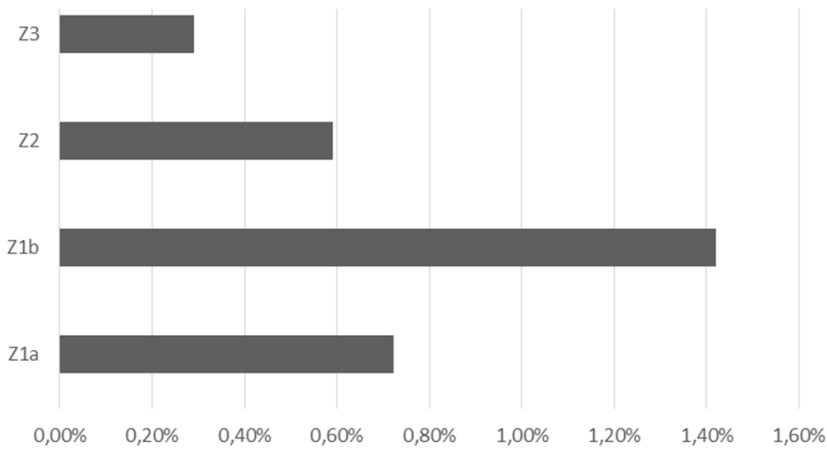

Fig. 3. Relationship between investment in ESRBs and work budget by areas of action

Most of the cost in environmental biosecurity was in sectoring tasks. In critical areas it accounted for $26.89 \%$ of the budget, while in the rest of the areas it was $29.48 \%$. The largest investment in sectorization corresponds to small actions in critical areas, $40.64 \%$ of the budget of the work.

The increase in health and safety conditions on the site was detected in $93.7 \%$ of the cases, due to the improvement in aspects relating to order, cleanliness and the circulation of workers and materials in the area affected by the work.

\section{Conclusions}

It is necessary to bring together the efforts of all the professionals involved in order to achieve a level of prevention that is sufficient to prevent infections during the execution of works [22]. Those responsible for management must be involved in the safety of the works being carried out at the hospital [23].

The average impact of the biosecurity project on the construction budget in critical areas has been greater in small works than in large renovations. The measures aimed at sectoring the affected areas were heavy compared to other measures related to working methods.

The study presents the limitations of being confined to a specific territory and the possibility of under-reporting of incidents by those responsible for monitoring and evaluating the measures. The information provided by the study has provided a starting point for future actions to improve containment procedures and techniques.

New time planning techniques, based on Building Information Model (BIM) technology, help to improve planning and avoid gaps between the different works that may generate pollution risks [24].

\section{Acknowledgements}

The authors wish to acknowledge the European Social Fund and University of Extremadura for the support for this research work. This study has been carried out through the research project GR-18029 linked to the VI Regional Plan of Research and Investigation from the General Government of Extremadura 2017-2020.

\section{References}

[1] Sanchez-Barroso G., García-Sanz-Calcedo J. Evaluation of HVAC design parameters in high-performance hospital operating theatres. Sustainability, Vol. 11, Issue 5, 2019, p. 1493.

[2] Alexander J. A., et al. The role of organizational infrastructure in implementation of hospitals' quality improvement. Hospital Topics, Vol. 84, Issue 1, 2006, p. 11-21.

[3] Busch-Vishniac I.-J., et al. Noise levels in Johns Hopkins hospital. The Journal of the Acoustical Society of America, Vol. 118, Issue 6, 2005, p. 3629-3645. 
[4] Tsiou C., Efthymiatos G., Katostaras T. Noise in the operating rooms of Greek hospitals. The Journal of the Acoustical Society of America, Vol. 123, Issue 2, 2008, p. 757-765.

[5] Akansel N., Kaymakçi Ş. Effects of intensive care unit noise on patients: a study on coronary artery bypass graft surgery patients. Journal of Clinical Nursing, Vol. 17, Issue 12, 2008, p. 1581-1590.

[6] Zhang W. A Study of Dust Movement through Construction Barriers. Doctoral Thesis, Texas A \& M University, 2014.

[7] Gómez-Chaparro M., García-Sanz-Calcedo J., Armenta-Márquez L. Analytical determination of medical gas consumption and their impact on hospital sustainability. Sustainability, Vol. 10, Issue 8, 2018, p. 2948.

[8] Lago J., Falcón D. Workshop on hospitals under remodelation: an experience of contribution. Gestión y Evaluación de Costes Sanitarios, Vol. 3, Issue 4, 2002, p. 417-421, (in Spanish).

[9] Gaspar C., Mariano A., Cuesta J., et al. Outbreak of invasive pulmonary mycosis in neutropenic hematologic patients in relation to remodelling construction work. Enfermedades Infecciosas y Microbiología Clínica, Vol. 17, Issue 3, 1999, p. 113-118.

[10] Goebes M. D., Baron E. J., Mathews K. L., et al. Effects of buildings constructions in a hospital. Infection Control and Hospital Epidemiology, Vol. 29, 2008, p. 462-464.

[11] Dettenkofer M., Seegers S., Antes G., et al. Does the architecture of hospital facilities influence nosocomial infection rates? A systematic review. Infection Control and Hospital Epidemiology, Vol. 25, 2004, p. 21-25.

[12] Ioana-Andreea M., et al. Strategic management of biochemical and biophysical control structures and sustainability health achievement. Management Strategies Journal, Vol. 26, Issue 4, 2014, p. 92-99.

[13] Simmons B. P. Guidelines for the prevention and control of nosocomial infections. Guidelines for hospital environmental control. Infection Control and Hospital Epidemiology, Vol. 11, 1983, p. 183-199.

[14] Recomendaciones Para La Vigilancia, Prevención Y Control De Infecciones En Hospitales En Obras. Instituto Nacional de la Salud, Sociedad Española de Medicina preventiva, Salud Pública e Higiene y el Insalud, Madrid, 2000, (in Spanish).

[15] Sánchez-Payá J., et al. Nosocomial infection surveillance and control: current situation in Spanish hospitals. Journal of Hospital Infection, Vol. 72, Issue 1, 2009, p. 50-56.

[16] Guidelines for Design and Construction of Hospital and Health Care Facilities. Facility Guidelines Institute, The American Institute of Architects, Washington, 2001.

[17] Ruiz-Camps I., Aguado J. M., Almirante B., et al. Recommendations of the spanish society of infectious diseases and clinical microbiology (SEIMC) on the prevention of invasive fungal infection due to filamentous fungi. Enfermedades Infecciosas y Microbiología Clínica, Vol. 28 Issue 3, 2010, p. 141-210, (in Spanish).

[18] Molina J., et al. Bioseguridad ambiental en un hospital con grandes obras. 5 años de vigencia de la contaminación fúngica. Medicina Preventiva, Vol. 14 Issue 2, 2008, p. 11-17, (in Spanish).

[19] Benítez J. M. Bioseguridad ambiental en un hospital con grandes obras: medidas correctoras y organización de control. Todo Hospital, Vol. 229, 2006, p. 439-445, (in Spanish).

[20] Construction-related Nosocomial Infections in Patients in Health Care Facilities. Decreasing the risk of aspergillus, legionella and other infections. Canada Communicable Disease Report, Public Health Agency of Canada, v. 27S2. Ottawa, 2001.

[21] Robles M., Dierssen T., Llorca F. J., et al. Prevention of nosocomial infection of fungal origin: verification of the environmental biosafety in surgery rooms. Revista Clínica Española, Vol. 205, Issue 12, 2005, p. 601-606.

[22] García-Sanz-Calcedo J., Monzón P. Analysis of the economic impact of environmental biosafety works projects in healthcare centres in Extremadura (Spain). Dyna Colombia, Vol. 81, Issue 188, 2014, p. 100-105.

[23] Chyu M. C., Austin T., Calisir F., et al. Healthcare engineering defined: a white paper. Journal of Healthcare Engineering, Vol. 6, Issue 4, 2015, p. 635-648.

[24] Candelario-Garrido A., García-Sanz-Calcedo J., Reyes Rodríguez A. M. A quantitative analysis on the feasibility of 4D planning graphic systems versus conventional systems in building projects. Sustainable Cities and Society, Vol. 35, 2017, p. 378-384. 